\title{
Chronic kidney disease in sugarcane workers in Cameroon: a cross-sectional study
}

\author{
Martin E. Ekiti ${ }^{1,4^{*}}$, Jean-Berthelot Zambo ${ }^{1,2}$, Felix K. Assah' ${ }^{1}$, Valirie N. Agbor ${ }^{3}$, Krystel Kekay ${ }^{1}$ \\ and Gloria Ashuntantang ${ }^{1}$
}

\begin{abstract}
Background: Agricultural workers especially in sugarcane plantations have a high risk of chronic kidney disease (CKD). Little is known about CKD among sugarcane plantation workers in Cameroon. This study sought to evaluate the prevalence and identify factors associated with CKD in sugarcane plantation workers in Cameroon.

Methods: We conducted an analytic cross-sectional study including 204 adult workers at the sugarcane plantation complex in Mbandjock, Cameroon; over $500 \mathrm{~m}$ above sea level. Chronic kidney disease (proteinuria as estimated by urine dipstick analysis and/or estimated glomerular filtration rate $<60 \mathrm{ml} / \mathrm{min} / 1.73 \mathrm{~m}^{2}$ persistent after 3 months) was the outcome of interest. Those with abnormal results were seen again after 3 months to confirm the diagnosis. We evaluated the association between CKD and participant age, sex, contract-type, duration of employment, socio-economic status, workspace, exposure to agrochemicals, heavy metals and heat, selected risk factors and co-morbid conditions.

Results: The overall prevalence of CKD was 3.4\%. The factory workers were the most affected (7\%), compared to the field (2.4\%) and office workers (0\%). $2.9 \%$ of the participants had persistent proteinuria, mild in every case, and $0.5 \%$ of them had an estimated glomerular filtration rate $<60 \mathrm{ml} / \mathrm{min} / 1.73 \mathrm{~m}^{2}$. Age $\geq 40$ years was an independent predictor of CKD.

Conclusion: The prevalence of CKD among employees of the Mbandjock sugarcane plantation is low, probably reflecting the preventive measures against heat stress and dehydration in place.
\end{abstract}

Keywords: Chronic kidney disease, Sugarcane plantation workers, Sub-Saharan Africa, Cameroon

\section{Background}

Chronic kidney disease (CKD) is a major public health problem due to its high global prevalence (13.4\%) [1], and adverse outcomes such as end-stage renal disease (ESRD), cardiovascular disease (CVD), and premature death [2]. Diabetes mellitus, hypertension and chronic glomerulonephritis constitute the major causes of CKD worldwide [2]. The overall prevalence of CKD in Cameroon is unknown. However, prevalence rates of $10.9 \%$ and $14.1 \%$ have been reported in an urban and rural setting of the Western Region of Cameroon, respectively [3].

\footnotetext{
* Correspondence: ekitimartin@gmail.com

${ }^{1}$ Faculty of Medicine and Biomedical Sciences, University of Yaoundé I, P.O.

Box 1364, Yaounde, Cameroon

${ }^{4}$ Occupational Health Service, National Refining Company (SONARA), P.O. Box

365, Limbe, Cameroon

Full list of author information is available at the end of the article
}

Agricultural workers are considered a high risk population for CKD in several parts of the world. The prevalence of CKD in plantation communities in Central America, Egypt, India and Sri Lanka has been reported to exceed the global prevalence of CKD in the general population $[4,5]$. In El Salvador, Vela et al. showed a CKD prevalence of $50.2 \%$ in two farming communities [6]. Several plantations especially sugarcane plantations have been identified as risk environments. Torres et al. found a GFR $<60 \mathrm{ml} / \mathrm{min} /$ $1.73 \mathrm{~m}^{2}$ prevalence rate of $17 \%$ among male sugarcane plantation workers in Nicaragua [7], while Peraza et al. reported a similar prevalence rate of $18 \%$ among male sugarcane plantation workers in El Salvador [8].

In Cameroon, agriculture is a major occupation as the country hosts one of the three largest sugarcane farming regions in SSA [9]. To the best of our knowledge, there is no data on the prevalence of CKD among sugarcane 
plantation workers in SSA in general, and Cameroon in particular. With the aim of contributing to the knowledge in this area in SSA, we conducted this study to evaluate the prevalence and associated factors of CKD among sugarcane plantation workers in the Mbandjock sugarcane plantation in Cameroon.

\section{Methods}

\section{Study design, setting and sampling}

We conducted an analytical cross-sectional study from November 2015 to May 2016 at the sugarcane plantation (SOSUCAM) complex in Mbandjock, which is a town about $100 \mathrm{~km}$ north-east of Yaoundé, the capital city of Cameroon. Consenting adults having worked for the company for at least 6 months were eligible. Interns, pregnant and post-partum women and participants with insufficient laboratory data were excluded.

For our study, we used the following formula for cross-sectional studies to calculate the sample size:

$$
n=\frac{Z_{1-\alpha / 2}^{2} p(1-p)}{d^{2}}
$$

Where:

$\mathrm{n}=$ Sample size.

$\mathrm{p}=$ Expected proportion in population.

$\mathrm{d}=$ Absolute error or precision.

$\mathrm{Z}_{1-\alpha / 2}=$ Standard normal variate for significance (1.96 if type I error is limited to $5 \%$ ).

The expected proportion (p) of CKD patients in a rural general population in Cameroon, based on studies carried out by Kaze et al. is $14.1 \%$ [3]. We tolerated an absolute error (d) of 5\%. Using the above formula, the minimum sample size calculated was 187 study participants. We used a stratified random sampling method to select 204 participants with workspace (office, factory or field) being the stratification variable such that the representation of participants according to workspace was similar to that in the general working population (Fig. 1).

\section{Measurements}

Socio-demographic data and relevant elements of the past history such as contract-type (permanent, temporary, seasonal), duration of employment, workspace (office, factory, field), exposure (to agrochemicals, heavy metals and heat), personal and family history of risk factors (hypertension, diabetes, CKD, chronic use of herbal medicines, chronic use of non-steroidal anti-inflammatory drugs, alcohol use, tobacco use) were noted using pre-established questionnaires. Anthropometric parameters, blood pressure and body mass index measurement was done using standard methods in line with the WHO STEPS survey methods. Blood and urine samples were collected in the mornings before any job activity. After disinfecting each participant's hands, they were handed a clean dry urine cup and instructed on how to collect midstream urine. A random morning urine sample was collected for dipstick urinalysis (Mission ${ }^{\circ}$ Expert of $\mathrm{ACON}^{\circ}$ Laboratories, USA). Venous blood was collected for serum creatinine assay which was done in the biochemistry laboratory of the SOSUCAM medico-surgical center with a semi-automatic chemistry analyser (Mindray model No BA-88A) applying the kinetic Jaffe reaction within $12 \mathrm{~h}$. Capillary blood was used to measure blood sugar level.

After 3 months, urine dipsticks and serum creatinine assay were repeated for participants with abnormal results at baseline. GFR was estimated using the CKD-EPI eq. [10].

\section{Definitions}

CKD was defined as the persistence of proteinuria and/or GFR $<60 \mathrm{ml} / \mathrm{min}$ over a period of 3 months. Urine abnormalities were defined as the presence of $\geq 1+$ of protein, blood or leucocytes on dipsticks. Proteinuria was categorized as mild $(1+, 30-100 \mathrm{mg} / \mathrm{dl})$, moderate $(2+, 100-500 \mathrm{mg} / \mathrm{dl})$ or heavy $(3+,>500 \mathrm{mg} / \mathrm{dl})$. Factory workers were mainly those involved in preparing the material for the planting of the crop, those exploiting the harvested crop and those maintaining the factory. Field workers were those doing the actual planting, maintenance and harvesting of the crop. All backpack sprayers of pesticides, herbicides and fertilizers, and those who mixed and stored them were considered exposed to agrochemicals. We considered welders who work on lead pipes and laboratory technicians who use lead acetate to be exposed to heavy metals. All field workers and factory workers in the boiler section were considered exposed to heat. Participants who used NSAIDs and herbal medicines at least once every month were considered to be chronic users. Seasonal workers were those who were hired on a temporary basis during a particular season, either the harvest or planting season, whose contracts were suspended for the 3 month period between both seasons. Participants on anti-diabetic agents or having a fasting or random blood sugar level $>126$ or $200 \mathrm{mg} / \mathrm{dl}$ respectively were considered diabetic while those on antihypertensive medication or with a blood pressure $>140 / 90 \mathrm{mmHg}$ were considered hypertensive.

Socioeconomic status (SES) was evaluated using a questionnaire adapted from the Cameroon Demographic and Health Survey's household questionnaire [11]. Low SES described people living in lack who cook with wood and coal, live in mud houses with no basic electrical appliances. They earn very little and drink water of dubious quality. Middle SES described people who possess certain goods which are not particularly essential to survival for example a television, a radio, a portable gas cooker and a telephone. Generally they drink potable water but of public use. Their average monthly income is about 150,000 FCFA (\$250). High SES described 
Total working population $N=2947$

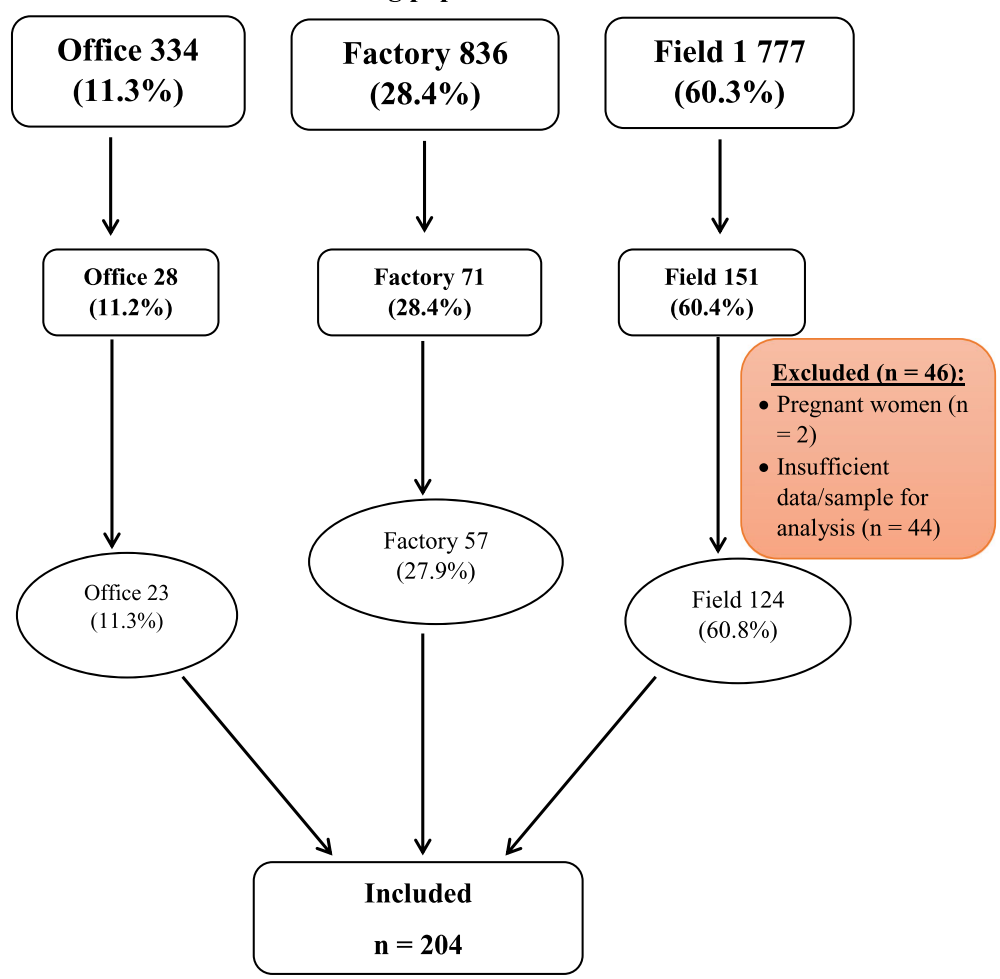

Fig. 1 Participant recruitment flowchart - To make our sample population representative of the general working population we randomly selected pre-numbered workers such that the proportions, with respect to workspace, were respected at every stage. In the first stage, we selected 250 participants. After excluding 46, we retained 204 participants, ensuring that the proportions remained approximately the same

people who have vehicles (motor bikes or cars), have individual water sources at home and are generally autonomous in terms of electricity supply. Their average monthly income is about 250,000 FCFA (\$430).

\section{Statistical analysis}

Data collected was analyzed using SPSS version 20 . Continuous variables were presented as means \pm SD or median with interquartile range (IQR) where necessary. Categorical variables were presented as frequencies and percentages. A two-sided Chi-squared, or Fisher's exact test where applicable, was used to compare qualitative variables. The Student t-test was used to compare means between two groups. A one-way analysis of variance (ANOVA), or the Kruskal-Wallis test where appropriate, was used to compare means or medians between the groups divided according to workspace. A multivariate logistic regression model was used to determine factors independently associated with CKD while controlling for confounders. The threshold of significance was set at 0.05 with $95 \%$ confidence intervals.

\section{Ethical considerations}

The study was approved by the Cameroon National Ethics Committee for Human Health Research. During an introductory meeting, the study was presented to each participant. They were each given an information sheet according to their language of choice (English or French) to read and those who had difficulties had the information explained to them by the principal investigator (EM). They each gave their written informed consent by signing the consent form.

\section{Results}

\section{General characteristics of the study population}

There were 2947 employed workers at the time of the study who met our eligibility criteria; 334 office workers, 836 factory workers and 1777 field workers. After sampling, we approached 252 workers to participate in the study two of whom refused to participate, giving an acceptance rate of $99.2 \%$. We then excluded 2 pregnant women and 44 participants for insufficient data for analysis leaving us with 204 participants (Fig. 1).

Of the 204 participants, $23(11.3 \%)$ were office employees, while 57 (27.9\%) and $124(60.8 \%)$ were factory and field workers respectively. The mean age of our participants was $39 \pm 10$ years and the median duration of employment was 10 years $[\mathrm{IQR}=9.75]$. The mean age and duration of employment were similar across all three workgroups. There were significantly 
more men (75\%) and seasonal workers $(73.5 \%)$ in all workspaces (Table 1).

As would be expected, field workers were more exposed to agrochemicals $(p<0.001)$ and heat $(\mathrm{p}<0.001)$ compared to the other workspaces whereas factory workers were significantly more exposed to heavy metals $(p=0.001)$ and they consumed more alcohol $(p=0.016)$. The mean body mass index (BMI) was $23.8 \mathrm{~kg} / \mathrm{m}^{2}, 23.2 \mathrm{~kg} / \mathrm{m}^{2}$ in men and $25.6 \mathrm{~kg} / \mathrm{m}^{2}$ in women. There were no diabetics and $<10 \%$ of the population had hypertension (Table 1).

\section{Urine abnormalities}

The most prevalent urine abnormality was proteinuria and its prevalence decreased from $15.9 \%$ to $2.9 \%$ after the post-interval tests (Fig. 2).

\section{Prevalence of CKD}

In all, 6 out of 204 (2.9\%) participants had persistent proteinuria which was mild in every case. One out of 204 (0.5\%) participants had persistent eGFR $<60 \mathrm{ml} / \mathrm{min}$. The mean serum creatinine was $1.09 \pm 0.16 \mathrm{mg} / \mathrm{dl}$ (range:

Table 1 Characteristics of sugarcane plantation workers according to workspace in Mbandjock, Centre Region, Cameroon, 2016

\begin{tabular}{|c|c|c|c|c|c|}
\hline Variable & $\begin{array}{l}\text { Total, n (\%) } \\
N=204\end{array}$ & $\begin{array}{l}\text { Office, n (\%) } \\
N=23\end{array}$ & $\begin{array}{l}\text { Factory, n (\%) } \\
N=57\end{array}$ & $\begin{array}{l}\text { Field, } \mathrm{n}(\%) \\
N=124\end{array}$ & $\overline{p \text {-value }}$ \\
\hline Sex & & & & & $<0.001$ \\
\hline Male & $153(75.0)$ & $17(73.9)$ & $55(96.5)$ & $81(65.3)$ & \\
\hline Female & $51(25.0)$ & $6(26.1)$ & $2(3.6)$ & $43(34.7)$ & \\
\hline Mean age (years) & $38.8 \pm 9.8$ & $40.6 \pm 11.5$ & $37.9 \pm 9.1$ & $38.9 \pm 9.8$ & 0.534 \\
\hline Contract-type & & & & & $<0.001$ \\
\hline CDI & $38(18.6)$ & $9(39.1)$ & $15(26.3)$ & $14(11.3)$ & \\
\hline CDD & $16(7.8)$ & $4(17.4)$ & $8(14.0)$ & $4(3.2)$ & \\
\hline CDC & $150(73.5)$ & $10(43.5)$ & $34(59.6)$ & $106(85.5)$ & \\
\hline Median duration of employment (years) & $10.0 \pm 7.8$ & $12.0 \pm 9.0$ & $10.0 \pm 7.3$ & $9.0 \pm 7.8$ & 0.257 \\
\hline Socio-economic status & & & & & 0.005 \\
\hline Low & $83(40.7)$ & $8(34.8)$ & 18 (31.6) & $57(46.0)$ & \\
\hline Middle & $103(50.5)$ & $9(39.1)$ & $32(56.1)$ & $62(50.0)$ & \\
\hline High & $18(8.8)$ & $6(26.1)$ & $7(12.3)$ & $5(4.0)$ & \\
\hline \multicolumn{6}{|l|}{ Exposure to: } \\
\hline Agrochemicals & $48(23.5)$ & $0(0.0)$ & $2(3.5)$ & $46(37.1)$ & $<0.001$ \\
\hline Heavy metals & $7(3.4)$ & $1(4.3)$ & $6(10.5)$ & $0(0.0)$ & $<0.001$ \\
\hline Heat & $130(63.7)$ & $0(0.0)$ & $9(15.8)$ & $121(97.6)$ & $<0.001$ \\
\hline Alcohol use & $167(81.9)$ & $20(87.0)$ & $53(93.0)$ & $96(77.4)$ & 0.031 \\
\hline Chronic use of NSAIDs & $134(65.7)$ & $13(56.5)$ & $39(68.4)$ & $82(66.1)$ & 0.589 \\
\hline Chronic use of herbal medicines & $132(64.7)$ & $15(65.2)$ & $41(71.9)$ & $76(61.3)$ & 0.379 \\
\hline Family history of CKD & $1(0.5)$ & $0(0.0)$ & $1(1.8)$ & $0(0.0)$ & 0.274 \\
\hline Obesity and overweight & $64(31.4)$ & $11(47.8)$ & $15(26.3)$ & 38 (30.6) & 0.165 \\
\hline Mean BMI $\left(\mathrm{kg} / \mathrm{m}^{2}\right)$ & $23.8 \pm 3.7$ & $24.6 \pm 4.4$ & $23.5 \pm 3.1$ & $23.8 \pm 3.8$ & 0.516 \\
\hline Tobacco use & $31(15.2)$ & $2(8.7)$ & $8(14.0)$ & $21(16.9)$ & 0.576 \\
\hline Hypertension & $20(9.8)$ & $4(17.4)$ & $3(5.3)$ & $13(10.5)$ & 0.236 \\
\hline Mean SBP $(\mathrm{mmHg})$ & $132.6 \pm 15.2$ & $137.1 \pm 21.7$ & $128.8 \pm 13.4$ & $133.4 \pm 14.3$ & 0.052 \\
\hline Mean DBP $(\mathrm{mmHg})$ & $79.6 \pm 10.1$ & $83.2 \pm 13.5$ & $78.6 \pm 9.0$ & $79.4 \pm 9.9$ & 0.171 \\
\hline Diabetes & $0(0.0)$ & $0(0.0)$ & $0(0.0)$ & $0(0.0)$ & - \\
\hline Mean FBS $(\mathrm{mg} / \mathrm{dL})$ & $90.3 \pm 13.5$ & $90.5 \pm 11.9$ & $94.2 \pm 14.3$ & $88.5 \pm 13.6$ & 0.458 \\
\hline Mean $\mathrm{RBS}^{\mathrm{a}}(\mathrm{mg} / \mathrm{dL})$ & $107.8 \pm 20.3$ & $111.5 \pm 15.2$ & $102.1 \pm 16.5$ & $109.8 \pm 22.2$ & 0.084 \\
\hline Mean serum creatinine $e^{a}(\mathrm{mg} / \mathrm{L})$ & $10.9 \pm 1.6$ & $10.6 \pm 1.3$ & $11.6 \pm 1.5$ & $10.6 \pm 1.6$ & $<0.001$ \\
\hline Mean eGFR $(\mathrm{ml} / \mathrm{min})$ & $109.6 \pm 20.5$ & $110.3 \pm 21.9$ & $107.9 \pm 16.5$ & $110.3 \pm 21.9$ & 0.760 \\
\hline
\end{tabular}

Conversion factors for units: serum creatinine in $\mathrm{mg} / \mathrm{dL}$ to $\mu \mathrm{mol} / \mathrm{L}, \times 88.4$

$B M I$ Body mass index CDI Permanent contract of non-specific duration, CDD Permanent contract of specific duration, $C D C$ Temporary/seasonal contract, $\mathrm{n}$ : Absolute frequency, eGFR Estimated glomerular filtration rate, NSAIDs Non-steroidal anti-inflammatory drugs

${ }^{a}$ Values based on measurements at baseline 


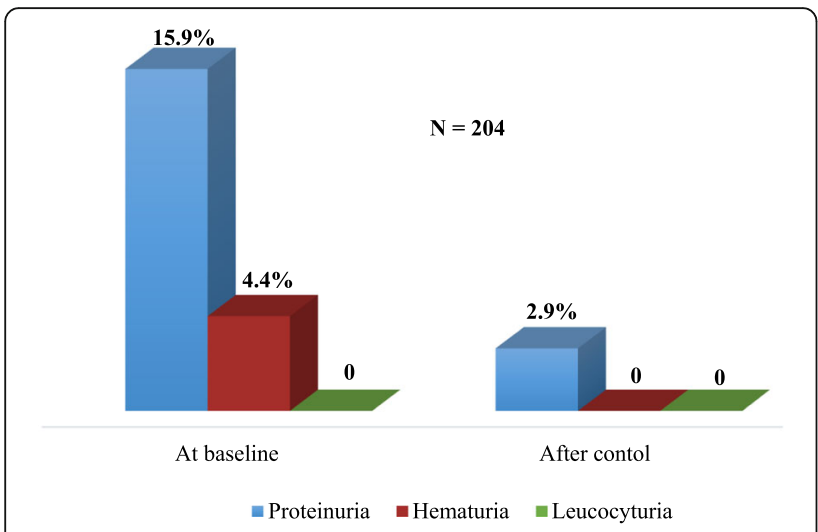

Fig. 2 Prevalence of urine abnormalities: The figure shows the change in prevalence of urine abnormalities (proteinuria, hematuria and leucocyturia) over time, from baseline to 3 months later after control tests were done

$0.78-1.75$ ) while the mean eGFR was $109.63 \pm 20.46$ (range: 48-168).The overall prevalence of CKD was 3.4\% [95\% CI $=1.0-6.0]$. The factory workers were most affected with a prevalence of $7 \%$ compared to the $0 \%$ and $2.4 \%$ of office and field workers respectively. Chronic use of herbal medicines $(p<0.001)$ and alcohol $(p<0.001)$ was significantly higher in the participants with CKD compared to their counterparts. Even after excluding the participant with an abnormal GFR, the participants with CKD had a lower GFR though the difference was not statistically significant (Table 2).

\section{Factors associated with CKD}

In bivariate analysis (Table 3$)$, age $\geq 40$ years $(p=0.032)$ and the use of herbal medicines $(p=0.045)$ were found associated with CKD. With a threshold of $p \leq 0.3$, we retained age, duration of employment, socioeconomic status, workspace, chronic use of NSAIDs, tobacco use and obesity/overweight as covariates for a binary logistic regression analysis (Table 3 ); after which, only age $\geq 40$ years was independently associated with CKD [OR $=18.7,95 \%$ $\mathrm{CI}=1.5-236.4, p=0.024]$.

\section{Discussion}

The aim of this study was to determine the prevalence and associated factors of CKD in a sugarcane plantation in Cameroon. We found a low CKD prevalence of 3.4\% with persistent non-nephrotic range proteinuria being the main marker of kidney damage. Age $\geq 40$ years was the only independent predictor of CKD in our study population.

The reported prevalence of CKD in plantation workers ranges from $2.3 \%$ [12] to $50.2 \%$ [6] depending on the definition of CKD, and the study setting. It is highest when the diagnosis of CKD is based on a single raised urinary protein excretion or serum creatinine, when the workers work for longer hours, are more exposed to heat and when the plantation is situated at a low altitude ( $\leq 300$ masl) [8]. Sugarcane plantation workers in Central America perform similar tasks and use similar agrochemicals to what we observed in our study but for a difference in the altitude of the study settings and the working conditions $[7,8,13-15]$. The study settings at higher altitudes ( $\geq 500$ masl) have temperatures about $4{ }^{\circ} \mathrm{C}$ lower than those at lower altitudes [13]. This difference in temperature means that the workers at lower altitudes are more exposed to heat and consequent dehydration which are some of the putative causes of CKD in these workers [4]. Our low prevalence at an altitude of $\sim 516$ masl, is consistent with recent findings in El Salvador which showed a prevalence of $4.2 \%$ for proteinuria and $2.5 \%$ for low eGFR $\left(<60 \mathrm{ml} / \mathrm{min} / 1.73 \mathrm{~m}^{2}\right)$, in a sugarcane farming community at a similar altitude of $\sim 500$ masl [8]. However, higher prevalence rates have

Table 2 Comparison of study population according to CKD status ( $N=204)$

\begin{tabular}{|c|c|c|c|c|}
\hline Variable & $\begin{array}{l}\text { Total } \\
N=204\end{array}$ & $\begin{array}{l}\text { CKD, N }=7 \\
\mathrm{n}(\%)\end{array}$ & $\begin{array}{l}\text { Non-CKD, N=197 } \\
\mathrm{n}(\%)\end{array}$ & $p$-value \\
\hline Mean age (years) & $38.8 \pm 9.8$ & $45.1 \pm 8.6$ & $38.6 \pm 9.8$ & 0.080 \\
\hline Mean SCr (mg/L) & $10.9 \pm 1.6$ & $12.6 \pm 2.5$ & $10.8 \pm 1.5$ & 0.003 \\
\hline Mean eGFR (mg/dl) & $109.6 \pm 20.5$ & $94.2 \pm 26.7$ & $110.2 \pm 20.1$ & 0.042 \\
\hline Mean eGFRa (mg/dl) & $109.9 \pm 20.1$ & $102.0 \pm 18.7$ & $110.2 \pm 20.1$ & 0.325 \\
\hline Alcohol use & $169(81.9)$ & $7(100.0)$ & $162(82.2)$ & 0.606 \\
\hline Chronic use of NSAIDs & $134(65.7)$ & $6(85.7)$ & $128(65.0)$ & 0.426 \\
\hline Chronic use of herbal medicines & $132(64.7)$ & $7(100.0)$ & $125(63.5)$ & 0.045 \\
\hline Overweight and obesity & $64(31.4)$ & $1(14.3)$ & $63(32.0)$ & 0.437 \\
\hline Tobacco use & $31(15.2)$ & $2(28.6)$ & $29(14.7)$ & 0.288 \\
\hline Hypertension & $20(9.8)$ & $1(14.3)$ & $19(9.7)$ & 0.520 \\
\hline Family history of CKD & $1(0.5)$ & $0(0.0)$ & $1(0.5)$ & 0.966 \\
\hline
\end{tabular}

CKD Chronic kidney disease, eGFR Estimated glomerular filtration rate, $n$ Absolute frequency, NSAIDs Non-steroidal anti-inflammatory drugs

${ }^{\mathrm{a} C}$ Comparison of the mean eGFRs excluding the one participant with eGFR $<60 \mathrm{ml} / \mathrm{min}$ 
Table 3 Factors associated with chronic kidney disease

\begin{tabular}{|c|c|c|c|c|c|c|c|}
\hline \multirow[t]{2}{*}{ Variable } & \multicolumn{7}{|l|}{ CKD } \\
\hline & $\overline{n(\%)}$ & OR & $95 \% \mathrm{Cl}$ & $p$ value & $\mathrm{AOR}$ & $95 \% \mathrm{Cl}$ & Adjusted $p$ \\
\hline Age $\geq 40$ years & $6(85.7)$ & 7.5 & $0.9-60.8$ & 0.032 & 18.7 & $1.5-236.4$ & 0.024 \\
\hline Male gender & $6(85.7)$ & 2.0 & $0.2-16.2$ & 0.442 & - & - & - \\
\hline Middle SES & $4(57.1)$ & 5.9 & $0.7-48.0$ & 0.062 & 5.0 & $0.5-45.7$ & 0.157 \\
\hline Duration of employment $\geq 15$ years & $3(42.9)$ & 2.1 & $0.5-9.0$ & 0.272 & 0.5 & $0.1-3.5$ & 0.442 \\
\hline Factory workspace & $4(57.1)$ & 3.4 & $0.8-14.9$ & 0.097 & - & - & 0.998 \\
\hline Seasonal work contract & $4(57.1)$ & 0.5 & $0.1-2.1$ & 0.384 & - & - & - \\
\hline \multicolumn{8}{|l|}{ Exposure to: } \\
\hline -Agrochemicals & $1(14.3)$ & 0.5 & $0.1-4.4$ & 0.480 & - & - & - \\
\hline -Heavy metals & $0(0.0)$ & - & - & 0.780 & - & - & - \\
\hline -Heat & $4(57.1)$ & 0.8 & $0.2-3.3$ & 0.498 & - & - & - \\
\hline Hypertension & $1(14.3)$ & 1.5 & $0.2-12.1$ & 0.520 & - & - & - \\
\hline Use of herbal medicines & $7(100.0)$ & - & - & 0.045 & - & - & - \\
\hline Alcohol consumption & $7(100.0)$ & - & - & 0.262 & - & - & - \\
\hline Obesity and overweight & $1(14.3)$ & 0.4 & $0.0-3.0$ & 0.297 & 0.2 & $0.0-2.2$ & 0.209 \\
\hline NSAID use & $6(85.7)$ & 3.2 & $0.4-27.4$ & 0.241 & 0.4 & $0.0-3.2$ & 0.350 \\
\hline Tobacco use & $2(28.6)$ & 0.4 & $0.1-2.3$ & 0.288 & 0.5 & $0.1-3.1$ & 0.470 \\
\hline
\end{tabular}

AOR Adjusted odds ratio, CI Confidence interval, CKD Chronic kidney disease, $n$ Absolute frequency, NSAIDs Non-steroidal anti-inflammatory drugs, OR Odds ratio, SES Socioeconomic status

been reported, especially in settings at lower altitudes. In Nicaragua, Torres et al. reported $10.3 \%$ with low eGFR [7] and in another setting at a lower altitude in El Salvador, Peraza et al. reported $12.4 \%$ [8]. The difference in altitude between their respective study sites (100 masl and 50 masl) compared to ours may explain this difference in prevalence. Putting our findings into the national context, our prevalence was lower than the $14.2 \%$ estimated prevalence in the general community in a rural setting in Cameroon [3]. The difference may be explained partly by the low prevalence rates of the traditional risk factors of CKD: diabetes, hypertension, overweight and obesity in our study population.

Kidney disease in agricultural communities has been observed to be tubulo-interstitial in nature, presenting with little or no proteinuria, and is suspected to occur sub-clinically even though eGFR values are within the normal range. We found a low $(2.9 \%)$ prevalence of proteinuria in our study population and when present, it was mild, in concordance with various studies irrespective of altitude $[8,14,15]$. We observed that the mean eGFR in the participants with CKD, though within the normal range, was significantly lower than in those without. This is expected, as the calculation of eGFR depends on serum creatinine which is a late marker of kidney damage, only increasing when kidney function has declined by about 50\% [16]. Other markers of kidney tubulo-interstitial injury have been identified such as neutrophil gelatinase-associated lipocalin (NGAL) and
$\mathrm{N}$-acetyl-beta-D-glucosaminidase (NAG) which may increase earlier in the course of the disease $[17,18]$. Assays of these markers in workers in Nicaragua showed an increase over a 6-month harvest period and they were each significantly associated with decrease in eGFR [15]. Control tests to confirm the chronicity of signs of kidney damage is important to prevent overestimation of CKD prevalence. In our study, about $85 \%$ of those with urine abnormalities showed none after post-interval tests. These findings imply that proteinuria and other signs of kidney damage are transient or acute, in support of the assertion that CKD in this risk group is due to recurrent episodes of acute kidney damage [19].

We observed that $57 \%$ of our participants with CKD worked in the factory. This contrasts with the predilection for field workers observed by Laws et al. in Nicaragua [14]. A difference in the working conditions in both settings may account for this difference. According to an independent report on the working conditions of sugarcane plantation workers in Nicaragua [20], the field workers worked for about $12 \mathrm{~h}$ a day, 7 days a week. These working conditions contrast with what we observed where workers typically are in the field for an average of $5 \mathrm{~h}$ a day, 6 days a week and usually finish their work around 10 a.m., before the sun is brightest and hottest. However, in our population, the factory workers work about $8 \mathrm{~h}$ a day, 6 days a week. Furthermore, the same report purports that workers have access to half the recommended amount of water under these 
circumstances by the United States Environmental Protection Agency [20]. In our setting, there are several $3000 \mathrm{~L}$ potable water tanks in the plantation within a walking distance of every field worker at any time. This ensures that workers have unlimited access to potable water throughout the workday which may be a protective factor for the field workers and may explain the differences observed.

Several factors have been associated with CKD in sugarcane plantation workers, including: older age, field work, working in lower altitudes, exposure to agrochemicals, increased duration of employment and chronic use of NSAIDs. Though chronic use of NSAIDs and herbal medicines were frequent potential risk factors irrespective of workspace, we found only age $\geq 40$ years to be an independent predictor of CKD. This is consistent with findings in El Salvador where age $>40$ years was a predictor of CKD [8]. We found no association between exposure to agrochemicals and CKD. This corroborates with the observation of Laws et al. in Nicaragua, who evaluated changes in eGFR over a 6-month period, and found that agrochemical applicators (those who are most directly in contact with agrochemicals) showed the least decline in eGFR compared to the workers in other job categories in the field [14]. This suggests that exposure to agrochemicals may not be a cause of CKD in this risk group. However, several studies [21-23] have shown a possible link of agrochemicals to CKD and hence it is a factor which needs to be studied more extensively. Even though, herbal medicines, alcohol and NSAIDs have been demonstrate as risk factors for CKD in similar settings $[3,24]$, we found no significant association between these factors and CKD in our study population. Yet other factors are suspected to be potential risk factors for CKD in similar populations, including leptospirosis infection, genetic factors, exposure to metals in volcanic soils etc. Though we did not assess them in our study, we believe they may play a role and hence should be further investigated.

\section{Limitations and strengths}

One of the limitations of our study was the small size of our study population. However, the representative random stratified sampling method we used, and our number of participants which exceeded the calculated minimum sample size, reduces sampling bias and hence permits the inference of our findings to the general working population in SOSUCAM. Furthermore, studies carried out in other countries like Nicaragua $(N=284)$ [14] and El Salvador $(N=224)$ [6] had similar sample sizes which assisted comparability of our findings. Furthermore, that we carried out our study in only one of the two sugarcane plantations in Cameroon potentially limits our work. However, the other plantation in
Nkoteng (also part of SOSUCAM), which is at an even higher altitude ( $\sim 580$ masl), performs similar practices with work conditions as described in the Mbandjock plant. Therefore, we believe our results can be generalised to reflect the situation of all sugarcane plantation workers. Despite these, our study is the first in Cameroon to describe the burden of CKD in sugarcane plantation workers and among the few reported in SSA. This therefore constitutes a significant contribution to the literature on CKD in Africa.

\section{Conclusion}

This study depicts a low prevalence of CKD among sugarcane plantation workers in Cameroon. Also, plantation workers aged 40 years and beyond are more likely to have CKD. Furthermore, our study accentuates the need for a control urine test in the evaluation of CKD prevalence in observational studies. Dehydration and heat stress being one of the putative risk factors for CKD in similar populations, we believe the practices in the company which serve to reduce their effects may play a role in protecting the workers from CKD. We recommend similar studies with larger sample sizes to be conducted in other plantations and other sub-Saharan countries so as to illuminate the true burden of CKD in this part of the world, as well as to identify the causative factors of CKD in sugarcane workers in particular.

\section{Abbreviations \\ ANOVA: Analysis of variance; BMI: Body mass index; CKD: Chronic kidney disease; CKD-EPI: Chronic kidney disease epidemiology collaboration; CVD: Cardiovascular disease; eGFR: Estimated glomerular filtration rate; ESRD: End-stage renal disease; IQR: Interquartile range; Masl: Meters above sea level; NAG: N-acetyl-beta-D-glucosaminidase; NECHHR: National ethics committee for human health research; NGAL: Neutrophil gelatinase-associated lipocalin; NSAIDs: Non-steroidal anti-inflammatory drugs; SD: Standard deviation; SOSUCAM: Cameroon sugar company; SPSS: Statistical package for social sciences; SSA: Sub-Saharan Africa; WHO: World Health Organization}

\section{Acknowledgments}

We would like to express gratitude to every worker who participated in this study. We would like to acknowledge Fidel Mbezo and Leopold N. Aminde who contributed to the statistical analysis and proofreading of the work, respectively.

\section{Funding}

The Cameroon Sugar Company (SOSUCAM) gave the principal investigator (EM) a monthly stipend (\$120) to subsidize room and board in Mbandjock. However, SOSUCAM had no role in the conception of the study; the collection, analysis and interpretation of data; in the writing of the report and the decision to publish the results.

\section{Availability of data and materials}

The dataset used and analyzed during the study is available from the corresponding author on reasonable request.

\section{Authors' contributions}

Research idea and study design: EM, AG, ZJB, AF, VNA, KK; Data acquisition: EM; Data analysis/interpretation: EM, AG, ZJB, KK; Statistical analysis: EM, AF; Supervision/ mentorship: AG, ZJB, VNA. Each author contributed important intellectual content during manuscript drafting or revision and accepts accountability for the overall work. All authors read and approved the final manuscript. 


\section{Ethics approval and consent to participate}

The study was approved by the Cameroon National Ethics Committee for Human Health Research (NECHHR), approval number: 2016/04/748/CE/ CNERSH/SP. All participants gave their informed consent by signing a written consent form.

\section{Consent for publication}

Not applicable.

\section{Competing interests}

The authors declare that they have no competing interests.

\section{Publisher's Note}

Springer Nature remains neutral with regard to jurisdictional claims in published maps and institutional affiliations.

\section{Author details}

${ }^{1}$ Faculty of Medicine and Biomedical Sciences, University of Yaoundé I, P.O. Box 1364, Yaounde, Cameroon. ${ }^{2}$ Cameroon Sugar Company (SOSUCAM), Mbandjock, Cameroon. ${ }^{3}$ Ibal sub-Divisional Hospital, Oku, Northwest Region, Bamenda, Cameroon. ${ }^{4}$ Occupational Health Service, National Refining Company (SONARA), P.O. Box 365, Limbe, Cameroon.

\section{Received: 17 August 2017 Accepted: 14 December 2017}

\section{Published online: 15 January 2018}

\section{References}

1. Hill NR, Fatoba ST, Oke JL, Hirst JA, O'Callaghan CA, Lasserson DS, et al. Global prevalence of chronic kidney disease - a systematic review and meta-analysis. PLoS One. 2016;11. Available from: http://www.ncbinlm.nih. gov/pmc/articles/PMC4934905/.

2. Levey AS, Coresh J, Balk E, Kausz AT, Levin A, Steffes MW, et al. National Kidney Foundation practice guidelines for chronic kidney disease: evaluation, classification, and stratification. Ann Intern Med. 2003:139:137-47.

3. Kaze FF, Meto DT, Halle M-P, Ngogang J, Kengne A-P. Prevalence and determinants of chronic kidney disease in rural and urban Cameroonians: a cross-sectional study. BMC Nephrol. 2015;16:117.

4. Almaguer M, Herrera R, Orantes CM. Chronic kidney disease of unknown etiology in agricultural communities. MEDICC Rev. 2014;16:9-15.

5. Lebov JF, Valladares E, Peña R, Peña EM, Sanoff SL, Cisneros EC, et al. A population-based study of prevalence and risk factors of chronic kidney disease in León, Nicaragua. Can J Kidney Health Dis. 2015;2. Available from: http://www.ncbi.nlm.nih.gov/pmc/articles/PMC4414463/. Accessed 21 July 2015.

6. Vela XF, Henríquez DO, Zelaya SM, Granados DV, Hernández MX, Orantes CM. Chronic kidney disease and associated risk factors in two Salvadoran farming communities, 2012. MEDICC Rev. 2014:16:55-60.

7. Torres C, Aragón A, González M, López I, Jakobsson K, Elinder C-G, et al. Decreased kidney function of unknown cause in Nicaragua: a communitybased survey. Am J Kidney Dis Off J Natl. 2010;55:485-96. Kidney Found

8. Peraza S, Wesseling C, Aragon A, Leiva R, García-Trabanino RA, Torres C, et al. Decreased kidney function among agricultural workers in El Salvador. Am J Kidney Dis Off J Natl. 2012;59:531-40. Kidney Found.

9. Crowe J, Wesseling C, Solano BR, Umaña MP, Ramírez AR, Kjellstrom T, et al. Heat exposure in sugarcane harvesters in Costa Rica. Am J Ind Med. 2013; 56:1157-64.

10. Levey AS, Stevens LA, Schmid CH, (Lucy) ZY, Castro AF, Feldman HI, et al. A new equation to estimate Glomerular filtration rate. Ann. Intern. Med. 2009;150:604-12

11. Institut National de la Statistique (INS) et ICF. International. Enquête Démographique et de Santé et à Indicateurs Multiples du Cameroun 2011. Calverton: INS et ICF International; 2012

12. Athuraliya NTC, Abeysekera TDJ, Amerasinghe PH, Kumarasiri R, Bandara P, Karunaratne $U$, et al. Uncertain etiologies of proteinuric-chronic kidney disease in rural Sri Lanka. Kidney Int. 2011;80:1212-21.

13. Weiner DE, McClean MD, Kaufman JS, Brooks DR. The central American epidemic of CKD. Clin J Am Soc Nephrol. 2013:8:504-11.

14. Laws RL, Brooks DR, Amador JJ, Weiner DE, Kaufman JS, Ramírez-Rubio O, et al. Changes in kidney function among Nicaraguan sugarcane workers. Int J Occup Environ Health. 2015;21:241-50.
15. Laws RL, Brooks DR, Amador JJ, Weiner DE, Kaufman JS, Ramírez-Rubio O, et al. Biomarkers of kidney injury among Nicaraguan sugarcane workers. Am J Kidney Dis. 2016;67:209-17.

16. Revista Panamericana de Salud Pública - End-stage renal disease among patients in a referral hospital in El Salvador [internet]. 2015. Available from: http://www.scielosp.org/scielo.php?pid=S1020-49892002000900009\&script= sci_arttext. Accessed 14 Sept 2015

17. Benchmark dose approach for renal dysfunction in workers exposed to lead - PubMed - NCBI [Internet]. Available from: http://www.ncbi.nlm.nih.gov/ pubmed/17497640. Accessed 24 May 2016.

18. Devarajan P. Neutrophil gelatinase-associated lipocalin (NGAL): a new marker of kidney disease. Scand J Clin Lab Investig Suppl. 2008;241:89-94.

19. Correa-Rotter R, Wesseling C, Johnson RJ. CKD of unknown origin in central America: the case for a Mesoamerican nephropathy. Am J Kidney Dis Off J Natl. 2014:63:506-20. Kidney Found

20. Fairfood International. "Treat Them Sweet. Fairfood International". 2014. Retrieved from http://www.fairfood.org/wp-content/uploads/2015/02/Treat Them_Sweet_Issue_Briefing_Fl.pdf.

21. Orantes $C M$, Herrera $R$, Almaguer M, Brizuela EG, Hernández $C E$, Bayarre $H$, et al. Chronic kidney disease and associated risk factors in the Bajo Lempa region of El Salvador: Nefrolempa study, 2009. MEDICC Rev. 2011;13:14-22.

22. Orantes $\mathrm{CM}$, Herrera $\mathrm{R}$, Almaguer M, Brizuela EG, Núñez $L$, Alvarado NP et al. Epidemiology of chronic kidney disease in adults of Salvadoran agricultural communities. MEDICC Rev. 2014;16:23-30.

23. Raines N, González M, Wyatt C, Kurzrok M, Pool C, Lemma T, et al. Risk factors for reduced glomerular filtration rate in a Nicaraguan community affected by Mesoamerican nephropathy. MEDICC Rev. 2014;16:16-22.

24. Ramirez-Rubio O, Brooks DR, Amador JJ, Kaufman JS, Weiner DE, Scammell MK. Chronic kidney disease in Nicaragua: a qualitative analysis of semi-structured interviews with physicians and pharmacists. BMC Public Health 2013:13:350

\section{Submit your next manuscript to BioMed Central and we will help you at every step:}

- We accept pre-submission inquiries

- Our selector tool helps you to find the most relevant journal

- We provide round the clock customer support

- Convenient online submission

- Thorough peer review

- Inclusion in PubMed and all major indexing services

- Maximum visibility for your research

Submit your manuscript at www.biomedcentral.com/submit
Biomed Central 